\title{
A DOUTRINA DO CONHECIMENTO DE NICOLAI HARTMANN
}

\section{Valério Rohden}

No primeiro volume da sua Ontologia, Nicolai Hartmann observa que, com o fracasso da metafísica especulativa proAlamado por Kant, os problemas metafísicos de modo algum desapareceram, mas se tornaram, antes, mais visíveis e ineviltaveís como sempre. E acrescenta: "Êstes problemas, porém, Ĵ̉ nẫo jazem no além-mundo, nem tampouco para lá de tôda experiência e dado, mas sim na proximidade mais imediata, langiveis, no meio da vida. Pendem de todo experimentável, acompanham o cognoscível em todos os domínios. Pois em todos os domínios se acha o cognoscivel dentro do marco do Incognoscivel. E porque as conexões do ser não se detêm nos limites do conhecimento, mas os transcendem por tôdas as partes, aparecem no fundo de todos os domínios as questões residuais, não resolvidas e insolúveis, e tôda investigação tropeça sem querer em algum ponto com elas, seja qual fôr a direção para a qual marche por obra do seu conteúdo."

A nossa exposição circunscrever-se-á aos problemas levantados pela obra Principios de uma metafísica do conhecimento (Grundzüge einer Metaphysik der Erkenntnis), de 1921, com a qual Hartmann assinala o seu afastamento do neokantismo da escola de Marburgo e estabelece as bases para uma filosofia do ser de natureza realista. Abordaremos os seguintes aspetos: I - O ponto de partida da experiência; II — A essência metafísica do problema do conhecimento; III - A noção de problema e a aporética; IV - O nôvo sentido de objeto e o centro de gravitação do conhecimento humano; $\mathrm{V}$ Os princípios do conhecer e do ser. 
I - O ponto de partida da experiência

O nosso conhecimento está orientado para o real. Ele, como a metafísica, não é dedutivo. Só ao fim de um longo processo discursivo poderemos esperar dizer o que o real é, o que o ser é. A filosofia primeira, que tratava dos princípios primeiros do ser, é para nós uma filosofia última, porque não é o ser que se funda sôbre o conhecer e sim êste sôbre aquêle, de tal modo que o conhecimento seja um progressivo avançar e tender ao além-objetivado, ao além-limite, a uma coincidência com o todo. O lento avançar do conhecimento tem sentido em confronto com uma paulatina revelação do ser.

A dimensão fundamental da receptividade, pela qual a verdade se impõe à consciência, atesta o mesmo ponto de partida. O conhecimento não é criação, êle é encontro, esbarramento com algo distinto, autônomo, anterior a êle. Enquanto apreender, o ato de conhecimento é receptividade e reconhecimento de uma realidade que o precede.

Uma filosofia guiada pela experiência e que evita tomadas de posição prévias, acha-se despojada da idéia de sistema. Um certo ponto de vista inicial é inevitável, mas êle deve ser mantido no mínimo e ser antes o objetivo a alcançar. A sistematização do conhecimento é uma tendência natural do nosso espírito e ela é inerente, até certo ponto, à natureza dos problemas, que formam entre si uma unidade fundamental de conteúdo. Mas ela deve realizar-se por si, pelo paulatino impor-se da verdade do ser ao conhecimento e a progressiva coincidência do ser dêste com o ser. Definindo-se como apreensão de um ente, o conhecimento humano é a posteriori.

Os problemas últimos para nós dependem todos da base primeira que os sustenta. O nosso filósofo distingue entre primeiro em si e primeiro para nós. Os princípios do ser e do conhecimento são primeiros em si, porque dêles depende o nosso conhecimento de todos os instantes. Mas são os últimos que nós apreendemos. Começamos pelo secundário no ser, pelo sensível mais próximo, e remontamos ao mais distante à nossa reflexão, que funda, no entanto, o sensível e a propria reflexầ, Por fraso o ser como tal, embora em al 0 mai presente, é o último que vamos compreender come tał. A ratio essendi e a ratio oognoseendi nâo colneidem, mal ati: am em ordem inversa. Mais ou menos como em Heseli 0 absoluto é aquêle que me está às costas, produz a atuaệa da minha consciência e é o último a que eu chego pela volia da consciência a sí.

O êrro da antiga ontologia fol querer deduzir todo 0 real de alguns principios primeiros e evidentes por si. 0 conteúdo da filosofia primeira não pode ser o primeiro ni ordem do conhecimento. Como o primeiro na ordem do ner, é o último que nós conhecemos. A metafísica ó, portanto, en quanto filosofia primeira na ordem do ser, uma fllosofia at tima na ordem do conhecer. Da mesma maneira nấ colnę dem o conhecimento e a exposição sôbre êle. O conhecimento deve já ter-se dado para que nós reflitamos sobre de ele 0 captemos nos seus fundamentos.

Embora o conhecimento a posteriori seja o main natil ral ao homem, não é por isso o mais fàcilmente explieâvel. O natural é o menos compreensivel por causa da sua imedian tez e da naturalidade com que a consciência aceita a sua obje: tividade. Por isso, embora tenham desaparecido nêle of pro: blemas do conhecimento a priori e sua validez objetiva, a justificação do impírico como ponto de partida mals segumo é, na realidade, o problema mais dificil. O conhecimente a priori, para poder aplicar-se ao real, deve pressupor a sensis ção como ponto de referência fixo das suas conexồe: bora a ciência e a filosofia desconfiem da sensação ao formü larem suas leis, constitui esta uma fonte sem par do sabei das coisas. Ela propicia a consciência da realidade e o juizo de existência, sendo o testemunho para nós de uma realidade substancial. A margem que ela oferece ao ceticismo deve nei compensada pela investigação das condições que a fundam.

O conhecimento a priori e o conhecimento a posteriori completam-se entre si e formam o conhecimento objetlvo aca: bado. A sua objetividade é garantida pela relação psicofiliea fundamental, que une corpo e alma no homem. 
De acôrdo com um pensamento de Cornélio Fabro, o ner é o único prius absoluto, que antecede qualquer análise a Hintese. É aquêle no qual a consciência está originalmente, mas aínda sem a plena posse de si mesma. A consciência só se move e progride de dentro do ser mesmo.

\section{II - A essência metafísica do problema do conhecimento}

A obra de Nicolai Hartmann procura estabelecer uma novn fundamentação do problema do conhecimento. Para lograr essa fundamentação, êle opõe-se, antes do mais, ao subjetivismo racionalista da filosofia moderna, que entendeu o objeto como criação do conhecimento e identificou simplesmente conhecimento e ser. Hartmann reafirma a primazia do er e a fundamentação do conhecimento nêle: "O conhecimento năo é criação, produção ou iluminação de um objeto, eomo quer ensinar-nos o idealismo de antigo e nôvo cunho, mas uma apreensão de algo que existe ainda antes de todo conhecimento e é independente dêste." o conhecimento, nesia frase, é definido como apreensão. Apreensão implica presuposiçấo de uma existência anterior ao ato de apreender, como própria condição dêste. Sem uma realidade em si, não existe conhecimento, mas pura ilusão e fantasia. O conhecimento é sempre conhecimento de um em si, sem esgotamento dele - pois não existe coincidência total entre ambos - é apreensẩo sempre nova dêle, conhecimento fenomenal do em si, mas conhecimento do em si. O ser não se identifica com o fenômeno, porque transcende sempre tôdas as suas manifestacốes. Esta experiência fundamental vai explicar o caráter metafisico de tôda a relação de conhecimento. Como iremos ver mais adiante, o conhecimento é sempre uma relação de her movido, em todos os seus atos, por um resíduo últime do real que sempre the escapa e o leva a retomar-se incessantemente, permanecendo em constante desequilibrio, na

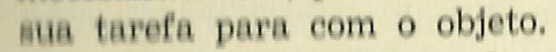

Por taso o problema do conhecimento é metafísico e uma taoria do conhecimento nấo pode deixar de ser metafisica. A teoria do conhecimento nấo deve constituir um prolegô- meno à metafísica, mas ela deve já ser metafísica. Aqui há uma oposição a tôda a concepção da filosofia desde Kant, que instaurava uma crítica do conhecimento como ponto de partida da metafísica. Kant afirmou que não há metafísica sem crítica. Para Hartmann isso é inteiramente verdadeiro, desde que se admita também o inverso - de que não há crítica sem metafísica. Kant, efetivamente, realizou uma crítica da razão à maneira de metafísica do conhecimento. Tôda a sua determinação das formas e conceitos a priori, como o problema da sua validez objetiva, são metafísicos; com a diferença que Kant fundou tudo na consciência transcendental e Hartmann fundou essa mesma consciência no ser. Uma metafísica crítica é prolegômeno indispensável da teoria do conhecimento. Trata-se de esclarecer em que consiste essa metafísica critica.

"Metafísica do conhecimento - assim iniciou êle o prefácio à primeira edição da sua obra - pretende ser uma denominação da gnosiologia, melhor do que crítica do conhecimento: não uma nova metafísica cuja base seja o conhecimento, mas pura e simplesmente uma gnosiologia cuja base é metafísica." Mais adequadamente dito, gnosiologia e metafísica são interdependentes e se fundam reciprocamente.

A essência do conhecimento é metafísica. Isto significa duas coisas: que o conhecimento é sempre uma apreensão de ser e que o conhecimento possui os seus princípios no ser mesmo. Por isso, vencendo tôdas as interpretações psicologistas anteriores, temos que dizer que "o problema do conhecimento não é psicológico, nem lógico, mas, no fundo, metafísico. Os elementos lógicos e psicológicos estão presentes em todo conhecimento, mas não constituem de modo algum a sua essência. Se o conhecimento é uma apreensão de ser, o fenômeno gnosiológico da apreensão está implicado com o ser que apreende. Por isso o problema do conhecimento figura entre as questões últimas relativas ao ser e seu sentido. É mesmo um dos problemas de mais difícil explicação..."

Esta nova colocação do problema do conhecimento não differe das outras apenas metodológicamente. Ela encerra uma enneepeño nova tanto do conhecimento como da metafísica. 
Para que esta nova concepção do conhecimento se torne mais evidente, cumpre esclarecer o que Hartmann entende por metafisica: 1) Uma metafísica chamada metafísica de setôres, que tinha na ontologia o seu núcleo fundamental e na cosmologia, psicologia e teologia os seus setôres especiais. Se se quisesse manter êsse tipo de metafísica, a sua divisão precisaria ser refeita. 2) Uma metafísica especulativa, ou seja, a mesma metafísica anterior, criticada por Kant, não por se dividir em setôres, mas por oferecer dogmàticamente uma Górie de soluções sôbre uma série de problemas. 3) Daqui decorre um terceiro tipo de metafísica, inspirada na crítica. kantiana e chamada por Hartmann metafísica de problemas. Eista metafísica, que Hartmann pessoalmente assume, entende que certos problemas nunca podem resolver-se totalmente e conservam, portanto, um resíduo impenetrável, irracional. Os problemas dessa índole são chamados metafísicos (problemas da vida, do ser, como o próprio problema do conhecimento em seu fundo). Todos os problemas filosóficos são, em вแล essência, problemas metafísicos. Possuem todos um interêsase central para a teoria do conhecimento, enquanto dizem respelto aos limites de cognoscibilidade. São chamados de problemas perenes, porque nenhuma filosofia os resolveu.

O lado objetivo do ser é constituído pela ontologia. A metafisica lida com problemas insolúveis. Como entender uma tese tho paradoxal? Que razão de ser teria ainda um tal tipo de metafisica? Como entender que a realidade se apóie sôbre Iim fundo irracional e eternamente problemático? Vem em auxilio desta questão a noção de problema, que se acha entre

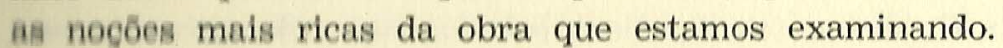

\section{1 - A noģa de problema e a aporética}

Nâo quer Hartmann dizer com isso que a filosofia se limite a levantar problemas. O que se tem de ter presente, porêm, ế que a boa colocaçấo dos problemas é condição indispenaîvel đa sua soluçăo. Aristóteles era um homem que năo he apressava a busca de soluçōes, mas sua arte era discutir bem og problemas, $\mathrm{A}$ análise dos problemas, mesmo de pro- blemas insolúveis, faz surgir uma série de outros e também novas soluções. O homem, como ser limitado diante do ilimitado, só entende os fenômenos até certo ponto. Tudo o que passe dêsse limite é-lhe dado sob forma de problema. O que se acha aquém dêsse limite é o que nós chamamos simplesmente conhecimento. Êsse limite, porém, é móvel. Retrocede à medida que os problemas vão sendo resolvidos. Cada solução muda a situação dos problemas e permite ao homem penetrar mais profundamente no desconhecido. O próprio conteúdo dos problemas, que se apresenta sempre mais determinadamente com cada avanço do saber, é que guia o homem nesse caminho.

É o homem quem levanta os problemas, mas o seu conteúdo não é obra do homem. "O homem é de modo algum dono do conteúdo do problema. No conteúdo do problema não existe nada que seja obra do homem. Está dado com a estrutura do mundo em geral e com a posição do homem nêle; só pode alterar-se, modificar-se algo dêsse conteúdo, se se modificarem em suas bases o próprio mundo e o homem nêle." A história dos problemas diz respeito não ao seu conteúdo, mas à sua colocação. Com um conteúdo dado com a estrutura da realidade, êsses problemas são metafísicos por natureza. Nem tudo, porém, é metafísico nêles; apenas os seus resíduos últimos. Neste sentido, "a metafísica é o trabalho filosófico que se faz nesse fundo que nunca é totalmente penetrável. Não se deve pensar que êsse trabalho seja vão. É a visão do limite que torna as coisas aquém dêste limite realmente visiveis e compreensiveis. Neste sentido também se deve entender o título de metafísica do conhecimento, como aquêle trabalho filosófico que se exerce sôbre o eterno conteúdo do próprio problema do conhecimento.

O problema específico da gnosiologia é o da apreensão do objeto, em que a gnosiologia se distingue da lógica e da psicologia. O problema do conhecimento em sentido estrito está implicado com a questão ontológica do modo de ser do objeto que se apreende. O fato de que o problema do ser está indissolúvelmente ligado ao do conhcer em sentido estrito torna o problema do conhecimento problema motafisico. 
Caber-nos-ia perguntar de nôvo que é êsse irracional que forma o conteúdo irredutivel dos problemas metafísicos? Não 10 trata de um modo de ser diferente do racional e nem constitui tampouco um limite fixo. Não se nega que êle não aeja racional em si mesmo, apenas é irracional para nós. "O Irracional não é um fantasma teórico nem um asylum ignorantiae metafísico, mas a expressão simples forjada prós hemás para o ser em geral, sempre que êste não se dissolva nos limites do cognoscivel. Em si não é mais metafísico que o raclonal, do qual é continuação homogênea." O conhecimento possui um caráter essêncialmente transcendente. O que o move a progredir sempre é o próprio enigma essencial da realidade com a qual êle aspira coincidir.

A relação ontológica do conhecer ao ser deve ser elaborada criticamente. Esta tarefa é a que cabe a uma metaIIslen eritica realizar. Na concepção de uma metafísica críliea ou ontologia crítica fundando o conhecimento, crítico signiflea ter de retroceder para antes de qualquer tomada de posith้ próvia, seja ela realista ou idealista, deixando guiar-se apenas pelo que o dado do fenômeno do conhecimento ofevecer, Critico significa que o ponto de partida será determinade desde o conteúdo dos problemas. Na obra de Hartmann; encontramos uma complementação sucessiva e rigorosa de fenomenologia, crítica e metafísica. A fenomenologia far-nos-á ver o dado em todos os seus aspetos. A crítica problemativâ-lo-Á e a metafísica consistirá na tomada de posição ante o conteúdo de ser dado nesses problemas. Essas três formas conjuntas de determinação do dado permitem apreender a verdadelra natureza de um objeto, no caso o conhecimento mesmo.

On problemas sẫo iniciamente aporias (do grego a-poria. ausêncla de caminho), quer dizer, caminhos fechados, que não apresentam inicialmente uma solução. A aporética é a ciêndị da bon colocaçấo dos problemas, da qual Aristóteles foi a madèlo eláselco, Ela consiste sobretudo num método de exame dor problemas como tais, sem se ocupar com a sua soheâlo, discerninde o compreendido do incompreendido e pon(1) À luy dificuldades e contradiçôes nos fenomenos presentes. 0) saber colocar as questồ है fâ um certo saber, inclusive do objeto, que na colocação se antecipa como para dar a direção, indicar o rumo.

A aporética acha-se indissolùvelmente ligada à fenomenologia, da qual recebe os materiais que irá problematizar. Ela não constitui nenhuma tomada de posição. É o seu trabalho que vai permitir desvendar a natureza do conhecido como a natureza metafísica do conteúdo dos problemas. Quanto maior a problematização e quanto maiores dificuldades se puserem à luz, maiores serâo as perspectivas de se chegar a uma solução. De modo que, se aporia significa ausência de caminho, a ulterior elaboração do problema implica precisamente em voltar a abrir caminho.

Que extensão deve ter o dado que escolhemos como ponto de partida? Uma solução adequada requer um ponto de partida adequado. Os positivistas dizem que "tudo é dado", enquanto para os idealistas "nada é dado". Ambas as posições desvirtuam a essência do conhecimento: A primeira cimento como apreensão Não é justo dizermos que nada seja nega o conhecimento como tarefa, a segunda nega o conhecimento como apreensão. Não é justo dizermos que nada seja dado e tampouco que tudo seja dado. Entre o dado e os seus resultados situa-se todo o trabalho da filosofia. Só o que antecede a êsse trabalho é dado efetivamente como ponto de partida. Apenas uma parte do todo é dada. Quanto mais dados, porém, tivermos, maiores possibilidades existem de êxito. E, inversamente, a solução será tanto mais difícil quanto mais reduzido fôr o campo de que eu parto, onde se torna impossivel o confronto e se corre o risco da solução unilateral, passando por cima de elementos essenciais.

Essa concepção deixa subentendido que além do dado, do questionado e do buscado, há algo não dado, não questionado ou não buscado neste momento, como condição da própria emergência do objeto. O objeto afunda suas raizes no ser que o transcende. Sem esta certa antecipação do ser no conteúdo dos problemas, correríamos o risco de identificar, cada vez, o objeto parcial com o ser em geral.

A problematizaçăo crítica do conhecimento revela alfumas aporias fundamentads, que sâ๋ as seguintes: 
1) Se sujeito e objeto possuem cada qual um ser em si, como pode a relação de conhecimento ser-lhes essencial?

2) Sujeito e objeto são transcendentes entre si. O mesmo se diz da relação entre ambos. Como se produz, então, yor ela, a unidade do ato do conhecimento?

3) Como pode a consciência manter a sua interioridade própria, se o conhecer é um sair de si?

4) Por outro lado, a transferência das determinações do objeto para o sujeito é tão enigmática como o sair do sujeito fora de si. Que é que se transfere do objeto, se o objeto é constituido a partir de um ente que se opõe à consciência como existente em si? Ou o conhecimento se anula ante a transcendência do objeto ou se anula a transcendência do objeto face à consciência.

Ao lado dessas aporias gerais, surgem as outras da pereepçâo, do ser dado, do conhecimento a priori, do critério da verdade, da consciência do problema, do progresso do conhecimento. Como pode haver, por exemplo, um saber de um nâo-saber? Como é possível apreender, mesmo sob a forma de problema, aquilo que permanece mais pròpriamente inapreendido? "Quem pergunta por algo não pode saber já o que pergunta; do contrário não necessitaria perguntar. $\mathrm{E}$, não obstante, tem de saber o que pergunta; senão nem poderia perGuntar por tal."

A última aporia do conhecimento é a aporia ontológica, escondida atrás da aporia gnosiológica: Como resolveremos o problema do conhecimento como tal, se a apreensão que conslitui a sua essência se dá sôbre o ser, que é um problema mail complicado ainda? Em que consiste essa relação de ser? Por isso podemos dizer com Hartmann que, "no problema do ronhecimento, há determinados pontos em que o problema gnosiológico passa em linha reta ao ontológico."

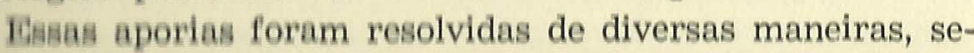
gundo os diferentes sistemas da História da Filosofia. Deternos-emos apenas na soluçâo do próprio Hartmann, particularmente na que diz respeito ao problema do dualismo gnoalelogice.
IV - O nôvo sentido de objeto e o centro de gravitação do conhecimento

Para Hartmann "o objeto não se esgota em ser objeto para a consciência". Êle possui um ser supra-objetivo, que lhe permite tanto tornar-se objeto como não se reduzir a objeto para uma consciência. O seu ser supra-objetivo torna a característica de objeto algo secundária para êle mesmo. "Não existe nenhum ente a cuja essência pertença ser objeto de uma consciência. Apenas com o aparecimento do sujeito cognoscente diante dêle, abandona êle a sua existência indiferenciada. O torná-lo objeto é o próprio do conhecimento. "Conhecimento existe apenas daquilo que uma vez é e que é independentemente que se conheça ou não". Isso faz-nos entender por que o ente não se esgota na relação de objeto.

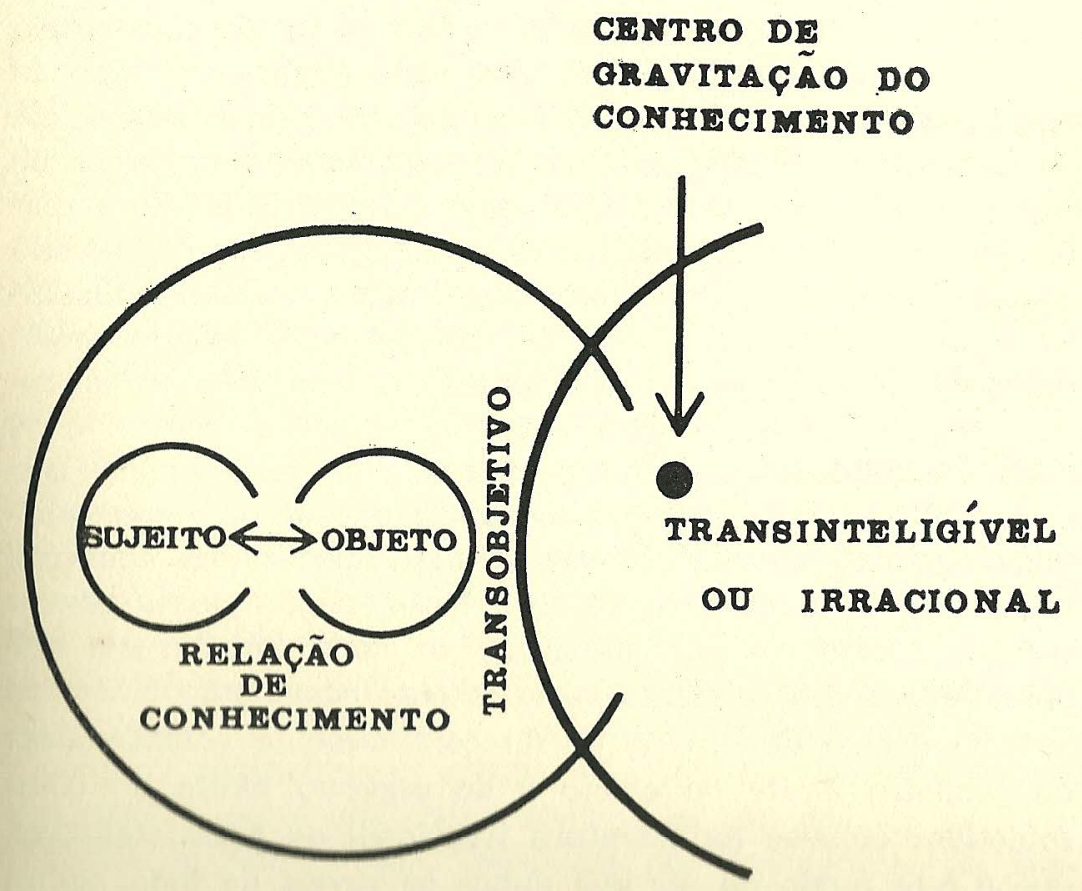

Segundo Kant, số se conhece o fenômeno, enquanto a coila em al fiea desconheoida, "Exatamente o contrário é o 
Justo, observa Hartmann. Conhecido é só, se é que há cothecimento, o ente em si. O fazer-se fenômeno, em troca, não e nada mais do que o conhecimento mesmo, apenas visto desde 1) objeto." O conhecimento define-se como conversão de um inte em objeto.

O objeto aparece sempre como o contrapêso da estrutura do conhecimento, mantendo sôbre ela a preponderância. E a lendencia permanente ao conhecimento faz supor uma infinitude sôbre a qual êle assente. Que é que me move, nesta lendência permanente ao conhecimento? Não só o ser diante de mim, que se torna problemático em tôda objetivação parHeular, mas também, por assim dizer, o ser atrás de mim. tiste ser mesmo, sôbre o qual a minha razão se apóia, me abraça.

A consciência apreende sintèticamente, no dado efetivo do objeto, a diferença entre a imagem e o objeto, entre obleto intencional e objeto real. A imagem coincide em conteú(10 com o objeto, embora ambos difiram quanto ao modo de Hei, Da minha consciência de tendência resulta a consciência (lo alêm e da entidade do objeto, revelando-se a estrutura de conhecimento como o aquém e como secundária frente à realidade a conhecer. A consciência manifesta-se em movimento eontinuo para um permanente, que sempre é. O ser, enquanto a da a nós desta e daquela maneira, é o próprio limite do conhecimento e o seu princípio. Oculta-se enquanto se revela, insere em si o objeto e nêle o conhecimento funda as 1uas posstbilidades. Achando-se inserida no ser, a razão não 6. pertanto, algo obstrato, mas aquela que, dado o seu caráter próprio de abertura, talvez possua mais intimas conexões póvias com a totalidade do real. Esta relação prévia com o 1odo, que longe está de constituir um conhecimento, é a que posibilita o conhecimento de cada ente como tal.

O centro de gravitação do conhecimento acha-se além (lo primeiro limite do objeto e do segundo limite do tranabjetive: acha-se na estrutura irracional ou transinteligivel, que é ête fundo do ser que nunca se revela de todo. Sobre de aอ exerce a tensto última da relaçăo de conhecimento. $A$ maperaęâ dêsse altimo residuo satisfarla a almejada visâo humana de totalidade, com a qual o homem compreenderia cabalmente o ser e renunciaria à sua finitude. Este último resíduo presente em todos os conteúdos de problemas, move, em ültima instância, todo o conhecimento, permitindo-lhe um progresso contínuo.

\section{$\mathrm{V}$ - Os princípios do conhecer e do ser}

O conhecimento encontra o seu principal problema no dualismo que o constitui. Tôda consciência requer um certo äistanciamento do seu objeto. Por outro lado, a relação de conhecimento implica a necessidade de ter algo em comum com aquilo que conhece. Se o dualismo é essencial, como o é a unidade, como se supera o dualismo e se elimina a distância para o encontro de consciência e coisa?

A solução da aporia reside na afirmação de uma identidade entre princípios do conhecimento e princípios do ser. O comum dos princípios permitirá a passagem ao diferente na relação de consciência e objeto. Esta solução de Hartmann encontra inspiração no princípio supremo dos juizos sintéticos estabelecido por Kant: "As condições da possibilidade da experiência em geral são a um tempo condições da possibilidade dos objetos da experiência, e possuem por isso valor objetivo em um juízo sintético a priori."

Kant limitou seu princípio aos fenômenos. Êle não vale para a metafísica, que fica assim definitivamente descartada. Revela, simultâneamente, o racionalismo de Kant, que, identificando absolutamente os princípios do conhecimento e do obje10, torna êste translúcido e resolve o conhecimento no conhecimento a priori. Êsse racionalismo, apesar de não se identificar com o idealismo, reduz, no entanto, o real a essências gerais, em que o particular se perde e já não é captado na sua riqueza, como acontece, em vez, no conhecimento a posteriori. O conhecimento a priori fornece as condições gerais dos objetos, daí a sua objetividade, mas não nos diz se e como êles de fato se dão. Deixa-nos por conseguinte, in abstracto.

Tentativas histórieas de identificar pensamento e ser eneontramos em Parmentdes, Fichte, Schelling e Hegel. Po- 
Alçồes mais moderadas, neste sentido, foram assumidas por Heráclito, Platão, Aristóteles, Espinosa e Leibniz.

O princípio de Kant possui uma significação para além de todo realismo e idealismo. $E$ expressa-se na solução de Ifartmann, segundo a qual o conhecimento possui princípios que em parte coincidem com os do ser real. E tanto o conhecimento como o ser real possuem princípios que não coincidem entre si (esfera irracional do ser real e do ser ideal.) A tese da identidade parcial pode ser assumida nos seguintel têrmos: "Havendo um conhecimento a priori de objetos reais, pelo menos uma parte das categorias de ser coincidem com as de conhecimento." Só essa coincidência torna posivel um conhecimento a priori com validez objetiva.

O conhecimento a priori, que é geral, refere-se ao cothecimento a posteriori, que é particular, e diz respeito, porInnto, ao conhecimento dêste objeto aqui e agora e de todos ol conhecimentos a posteriori futuros. O conhecimento a posterlori, $\delta$, no entanto, um problema a parte, nada mais fácil de explicar que o conhecimento a priori.

O conhecimento é êle próprio um modo de ser, "visto que a consciência é também um existente e está inserida na effera total do existente. Por conseguinte, as condições do conhecimento têm de estar de algum modo incorporadas ao aistema de condições do ser." Quer dizer, se o conhecimento pertence de algum modo ao ser, deve haver algumas condigoes que valham a um tempo tanto para o ser como para o conhecer, Em uma palavra, o ser é princípio de si mesmo e do eonhecimento.

"A possibilidade do apreender cabalmente, do ser dado, đa intuiçúo a priori, do critério, do problema e do progresso, estriba cabalmente na essência da coisa existente, do sujelto existente e da relação básica que abarca a ambos. O problema marginal último prós hemás afeta a base primeira

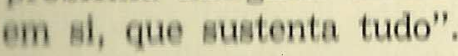

\section{Coneluado}

Também Ifusser e Heidegger superam, à sua maneira, a problema do dualismo gnosiológico. Para Husserl, a cons= ciência pertence sempre a um eu que já é parte do mundo. Ela é dada, desde o seu primeiro momento de consciência, como em. relação com um objetivo, de sorte que não poderíamos determinar um primeiro movimento dela neste sentido. O sujeito é sempre apreendido como pensando já um objeto. Concebendo a consciência como consciência de, Husserl diz que o mundo está já desde sempre presente à consciência, que a consciência, enquanto se constitui como consciência do mundo, se constitui como mundo mesmo. O mundo não é projeção da consciência, nem a consciência um retrato do mundo. Mundo e consciência são uma coisa só, antes do dualismo.

Para Heidegger, a relação sujeito-objeto é sempre posterior sôbre algo já dado. O Dasein já está sempre no mundo. Antes do conhecimento existe o já-estar-no-mundo.

É o que significa ser-no-mundo: que o Dasein não pode ser apreendido como um certo sujeito sem mundo, mas confiado já a um mundo. Um e outro não se acham isolados, porque existe desde sempre um comércio entre êles, cooriginário ao ser de ambos. De modo que o pôr-se em relação sujeito e objeto para conhecer o mundo é algo que vem muito tarde, porque ambos já estão em relação. O Dasein é-nomundo, isto significa exatamente que o ser do Dasein é assumido a partir do mundo, que é o mundo que estrutura o ser do Dasein. O mesmo poderia dizer-se, num plano mais radical, da relação homem-ser.

Com isso não se afirma que o homem como tal se dissolva no mundo. Como ser-no-mundo, êle distingue-se dos entes intramundanos pela sua transcendência peculiar. "Nós não dizemos simplesmente, observa Cornélio Fabro, que o homem depende do mundo enquanto mundo. Mas o homem depende do mundo enquanto no mundo se apresenta o ser. Porque quanto à forma de ser o homem é superior ao mundo. $\mathrm{E}$ é precisamente enquanto o homem é superior ao mundo, enquanto o homem é espirito que ao homem se apresenta o ser".

Nicolal Hartmann acentua que depois da Critica da raado pura se perdeu a fé na soluçấo dos problemas metafisicos tradicionals e assumiu-se, em substancia, uma atitude crí- 
tica que significasse a máxima ausência de tomada de posição possível, porque qualquer tomada de posição significaria um transcendimento metafísico da crítica. Essa tendência converteu-se no vício do criticismo.

O criticismo não era, porém, a intenção pessoal de Kant, o qual, embora negando a solubilidade dos problemas metafísicos, defendeu sempre a sua realidade inelutável.

A posição de Hartmann apresenta-se, no fim, muito semelhante à de Kant, com a diferença que êle faz uma confissão mais coerente de realismo, ao proclamar a realidade do em si, independente e anterior à consciência, como condição absoluta do conhecimento, se bem que êste conhecimento não se complete e se frustre naquilo que êle revela como sua natureza fundamental - a sua tendência metafísica. Porque o metafísico para êle é o fundo irracional da realidade e o eterno problema do fundo dos problemas, que nunca conseguimos resolver de todo.

Esta frustração da metafísica em Hartmann pode abrir margem a um certo ceticismo. Em verdade, encarado o problema sob outro aspeto, não há motivo para ceticismo. A realidade do ser tem de tornar-se experiência final de cada um e a própria inexauribilidade do real talvez ofereça a chave para a sua justa compreensão. 